\title{
Effect of variable circuit flow rate during the expiratory phase on $\mathrm{CO}_{2}$ elimination
}

This article was published in the following Dove Press journal:

Research and Reports in Neonatology

23 April 2012

Number of times this article has been viewed

Peter A Keszler'

Pankaj Nagaraj'

Kabir Abubakar'

Martin Keszler ${ }^{2}$

'Georgetown University, Washington, DC, USA; Georgetown University Hospital, Washington, DC, USA;

${ }^{2}$ Brown University, Women and Infants Hospital of Rhode Island,

Providence, RI, USA
Correspondence: Martin Keszler Women and Infants Hospital of Rhode Island, I0I Dudley Street, Providence, RI 02905, USA

$\mathrm{Tel}+\mid$ 40I 274 I I 22

Fax + I 40| 453757 I

Email mkeszler@wihri.org
Background: Some continuous flow infant ventilators allow independent setting of inspiratory and expiratory circuit flow rate. In the Dräger Babylog 8000+ ventilator, this is called "variable inspiratory, variable expiratory flow" (VIVE). Some clinicians believe that lower expiratory flow decreases expiratory resistance. The minimum expiratory flow rate needed to avoid re-breathing of carbon dioxide $\left(\mathrm{CO}_{2}\right)$ has never been established.

Objective: We sought to determine if re-breathing becomes evident at the lowest possible expiratory flow rate setting of $1 \mathrm{~L} / \mathrm{min}$.

Design/methods: We conducted a bench study using end-tidal $\mathrm{CO}_{2}\left(\mathrm{ETCO}_{2}\right)$ measurement and a $45 \mathrm{~mL}$ ( $90 \mathrm{~mL}$ for the "term" model) test lung pre-filled with $100 \% \mathrm{CO}_{2}$. We previously showed that the time needed for $\mathrm{ETCO}_{2}$ to be eliminated from the lung is a highly reproducible indicator of efficiency of ventilation. Re-breathing would thus be identified by an increase in the time required for the $\mathrm{CO}_{2}$ to be washed out from the test lung at stable settings of rate and tidal volume $\left(\mathrm{V}_{\mathrm{T}}\right)$. Using a Babylog $8000+$ ventilator in volume guarantee mode with VIVE and a standard ventilator circuit, we tested the effect of decreasing expiratory flow rate under conditions simulating three sizes of patients: extremely low birth weight infant, $\mathrm{wt}=600 \mathrm{~g}$ $\left(\mathrm{V}_{\mathrm{T}}=3.5 \mathrm{~mL}\right.$, respiratory rate $(\mathrm{RR})=60$ breaths $\mathrm{min}^{-1}$, minute ventilation $(\mathrm{MV})=210 \mathrm{~mL} / \mathrm{min}$, expiratory flow rate $=3 \mathrm{~L} / \mathrm{min}, 2 \mathrm{~L} / \mathrm{min}$, and $1 \mathrm{~L} / \mathrm{min}$ ), very low birth weight infant, wt $=1.5 \mathrm{~kg}$ $\left(\mathrm{V}_{\mathrm{T}}=7 \mathrm{~mL}, \mathrm{RR}=60\right.$ breaths $\mathrm{min}^{-1}, \mathrm{MV}=420 \mathrm{~mL} / \mathrm{min}$, expiratory flow rate $=4 \mathrm{~L} / \mathrm{min}, 3 \mathrm{~L} / \mathrm{min}$, $2 \mathrm{~L} / \mathrm{min}$, and $1 \mathrm{~L} / \mathrm{min})$, and term infant, wt $=3.6 \mathrm{~kg}\left(\mathrm{~V}_{\mathrm{T}}=16 \mathrm{~mL}, \mathrm{RR}=60\right.$ breaths $\mathrm{min}^{-1}$, $\mathrm{MV}=960 \mathrm{~mL} / \mathrm{min}$, expiratory flow rate $=5 \mathrm{~L} / \mathrm{min}, 4 \mathrm{~L} / \mathrm{min}, 3 \mathrm{~L} / \mathrm{min}, 2 \mathrm{~L} / \mathrm{min}$, and $1 \mathrm{~L} / \mathrm{min}$ ). Each measurement was repeated four times and the mean values were compared by analysis of variance for repeated measures.

Results: The $\mathrm{CO}_{2}$ elimination times were always within $10 \%$ of each other with each repetition. There was no significant increase in the elimination time even at the lowest flows.

Conclusion: Clinically significant re-breathing does not occur even with expiratory flow rate at the lowest possible setting of $1 \mathrm{~L} / \mathrm{min}$. VIVE is safe to use, although its clinical utility has not been established.

Keywords: mechanical ventilation, newborn, bench study, re-breathing, expiratory flow rate, end-tidal $\mathrm{CO}_{2}$

\section{Background}

The majority of ventilators currently in use in North America use demand flow during the inspiratory phase to meet inspiratory flow requirements and return circuit flow to a low baseline during the expiratory phase. The Dräger Babylog 8000+ (Dräger Medical, Lübeck, Germany) is a continuous flow infant ventilator that uses a continuous flow in the ventilator circuit throughout the respiratory cycle in the default mode, but 
provides a feature that allows the user to select an expiratory flow rate independent of inspiratory flow rate. This feature is called "variable inspiratory, variable expiratory flow rate" or VIVE. ${ }^{1,2}$ There are no published data to guide the use of VIVE. Many clinicians believe that lower expiratory flow rate decreases expiratory resistance and thus lowers the work of breathing, based on a paper suggesting that continuous flow ventilators may be associated with higher expiratory work of breathing. ${ }^{3}$ Although this may no longer be true with modern technology, VIVE remains a commonly used option on one of the most widely used neonatal ventilators and there are no data to guide the clinician in setting appropriate expiratory flow rate in VIVE. Whether or not it affects expiratory resistance, lower circuit flow during the expiratory phase would lower the consumption of medical gases and sterile water for humidification and may therefore be desirable. However, if the circuit flow rate during the expiratory phase were to fall below that, which is needed to sweep exhaled gas down the expiratory limb of the circuit, re-breathing of $\mathrm{CO}_{2}$ would occur and impair $\mathrm{CO}_{2}$ elimination.

We hypothesized that there is a minimum expiratory flow rate that is needed to avoid re-breathing of exhaled gas and therefore avoid impairing $\mathrm{CO}_{2}$ elimination and that this flow rate is related to the tidal volume $\left(\mathrm{V}_{\mathrm{T}}\right)$ and minute ventilation (MV) of the infant.

\section{Methods}

We conducted a bench study using a Dräger Babylog 8000+ continuous flow infant ventilator (Dräger Medical, Lübeck, Germany) with a standard Fisher and Paykel ventilator circuit and humidifier (Fisher and Paykel, Auckland, New Zealand). We pre-filled a $45 \mathrm{~mL}$ silicone rubber bellows test lung (IngMar Medical, Pittsburgh, PA) with $100 \% \mathrm{CO}_{2}$ and used a $\mathrm{CO}_{2} \mathrm{SMO}$ Plus respiratory monitor mainstream $\mathrm{ETCO}_{2}$ system (Novametrix Medical Systems, Wallingford, CT) to detect the rate at which $\mathrm{CO}_{2}$ was eliminated from the test lung (Figure 1). We previously showed that the time needed for $\mathrm{ETCO}_{2}$ to fall below $8 \mathrm{mmHg}$ (the threshold of reliable detection by this instrument) is a highly reproducible indicator of efficiency of ventilation in this model. ${ }^{4}$ The basic principle is that with the initiation of ventilation, $\mathrm{CO}_{2}$ is detected by the $\mathrm{ETCO}_{2}$ monitor at the airway opening, initially at high concentration when the test lung is filled with pure $\mathrm{CO}_{2}$. Subsequently, the $\mathrm{ETCO}_{2}$ declines in an exponential fashion as the $\mathrm{CO}_{2}$ concentration in the test lung decreases and therefore less $\mathrm{CO}_{2}$ is cleared from the test lung with each breath (Figure 2). The time needed for the $\mathrm{ETCO}_{2}$ to drop below the threshold of detection is proportional to effective alveolar minute ventilation.

Re-breathing would thus be identified by an increase in the time required for the $\mathrm{CO}_{2}$ to be washed out from the test lung (the $\mathrm{CO}_{2}$ elimination time) at any given $\mathrm{MV}$ determined by stable settings of respiratory rate $(\mathrm{RR})$ and $\mathrm{V}_{\mathrm{T}}$. We tested the effect of decrements in expiratory flow rate under conditions simulating three sizes of patients: extremely low birth weight infant, wt $=600 \mathrm{~g}\left(\mathrm{~V}_{\mathrm{T}}=3.5 \mathrm{~mL}, \mathrm{RR}=60\right.$ breaths $\mathrm{min}^{-1}, \mathrm{MV}=210 \mathrm{~mL} / \mathrm{min}$, expiratory flow rate $=3 \mathrm{~L} / \mathrm{min}$, $2 \mathrm{~L} / \mathrm{min}$, and $1 \mathrm{~L} / \mathrm{min}$ ), very low birth weight infant, $1.5 \mathrm{~kg}$ $\left(\mathrm{V}_{\mathrm{T}}=7 \mathrm{~mL}, \mathrm{RR}=60\right.$ breaths $\mathrm{min}^{-1}, \mathrm{MV}=420 \mathrm{~mL} / \mathrm{min}$, expiratory flow rate $=4 \mathrm{~L} / \mathrm{min}, 3 \mathrm{~L} / \mathrm{min}, 2 \mathrm{~L} / \mathrm{min}$, and $1 \mathrm{~L} / \mathrm{min}$ ),

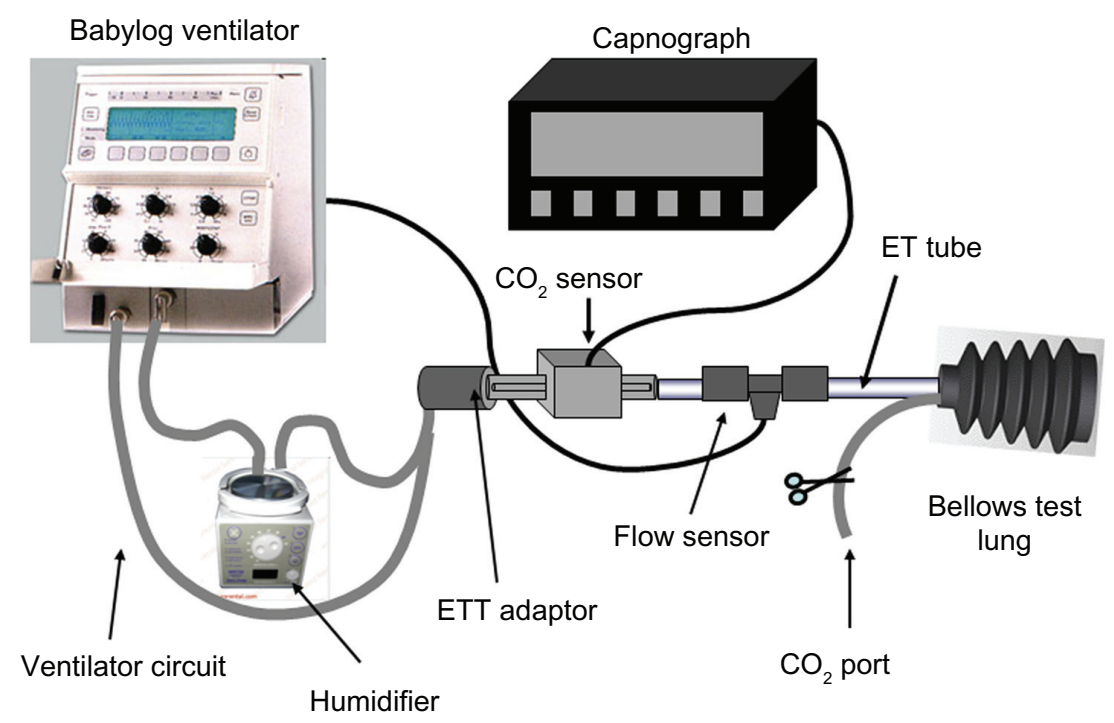

Figure I The experimental setup.

Abbreviations: ET, endotracheal; ETT, endotracheal tube. 


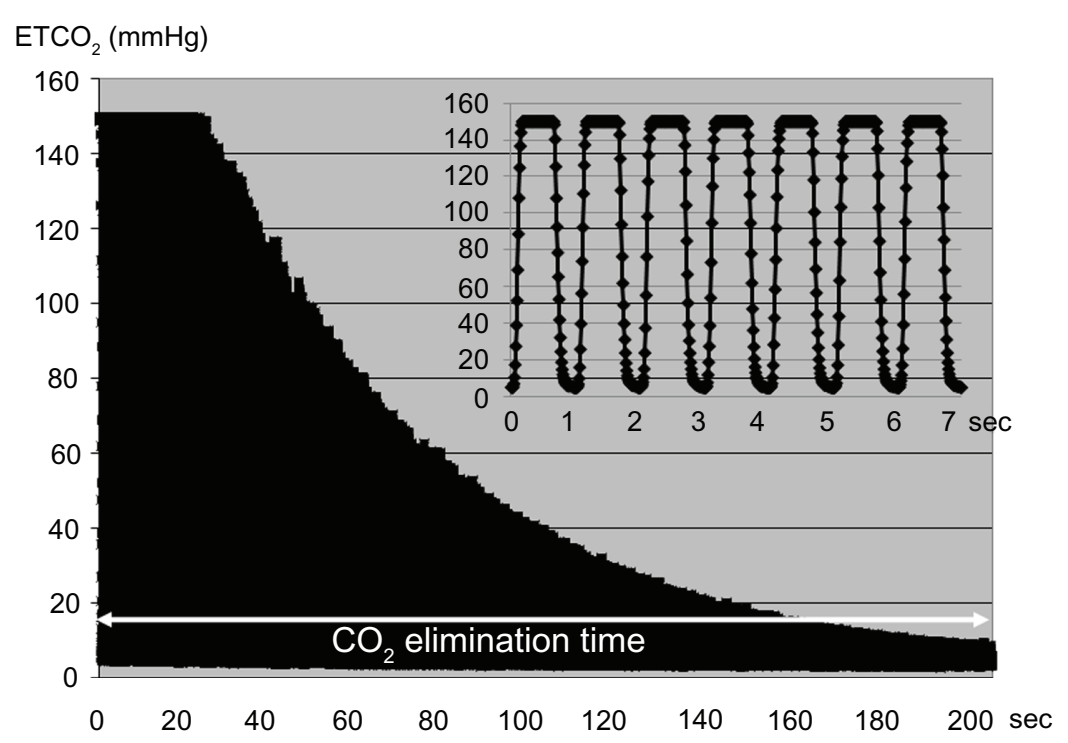

Figure 2 The smaller panel in the figure shows the $\mathrm{ETCO}_{2}$ waveform generated with each breath. The larger panel is a compressed waveform of a single trial (note the difference in time scale). The peak of the curve is flattened, because the upper limit of detection of the capnograph is $150 \mathrm{mmHg}$, while the actual ETCO value should be close to atmospheric pressure at the onset of ventilation when the lung is filled with pure $\mathrm{CO}_{2}$. The exponential decline in the readings is evident. Initially, at high $\mathrm{CO}_{2}$ concentrations, a larger amount of $\mathrm{CO}_{2}$ is eliminated with each breath, but as the level of $\mathrm{CO}_{2}$ drops, a progressively smaller quantity is removed, as indicated by progressively lower end-tidal $\mathrm{CO}_{2}$ values. The elimination time is a reflection of the effective alveolar ventilation.

Abbreviation: $\mathrm{ETCO}_{2}$, end-tidal $\mathrm{CO}_{2}$.

and term infant, wt $=3.6 \mathrm{~kg}\left(\mathrm{~V}_{\mathrm{T}}=16 \mathrm{~mL}, \mathrm{RR}=60\right.$ breaths $\mathrm{min}^{-1}, \mathrm{MV}=960 \mathrm{~mL} / \mathrm{min}$, expiratory flow rate $=5 \mathrm{~L} / \mathrm{min}$, $4 \mathrm{~L} / \mathrm{min}, 3 \mathrm{~L} / \mathrm{min}, 2 \mathrm{~L} / \mathrm{min}$, and $1 \mathrm{~L} / \mathrm{min}$ ). For the term infant model, a double bellows lung (volume $=90 \mathrm{~mL}$ ) was used because of the larger $\mathrm{V}_{\mathrm{T}}$ needed.

The ventilator circuit was connected to the $\mathrm{ETCO}_{2}$ sensor which was attached to one end of the Babylog flow sensor connected to a $2.5 \mathrm{~mm}$ endotracheal tube cut to $10 \mathrm{~cm}$ length and inserted tightly into the open port of the test lung. A $3.0 \mathrm{~mm}$ tube was used for the simulated $1.5 \mathrm{~kg}$ infant and $3.5 \mathrm{~mm}$ tube for the simulated term infant. The test lung connection had a side port that allowed filling of the test lung with pure $\mathrm{CO}_{2}$ prior to each test. Prior to each set of experiments, the flow sensor and $\mathrm{ETCO}_{2}$ monitor were calibrated according to manufacturers' instructions and tightness of all connections was verified. The test lung was flushed with $100 \% \mathrm{CO}_{2}$ at $2 \mathrm{~L} / \mathrm{min}$ for 2 minutes just prior to each trial to ensure that it was completely filled with pure $\mathrm{CO}_{2}$, the $\mathrm{CO}_{2}$ port was then clamped and the test lung was attached to the ventilator circuit taking care to minimize movement that might agitate the gas. The test lung was enclosed in an airtight plastic container to avoid inadvertent change in volume (ie, "spontaneous breathing"). The $\mathrm{ETCO}_{2}$ monitor was switched on and ventilation started in volume guarantee mode at a specific expiratory flow rate setting on VIVE. The inspiratory flow rate remained at $6 \mathrm{~L} / \mathrm{min}$; inspiratory time was set at 0.35 seconds, pressure limit at $30 \mathrm{~cm} \mathrm{H}_{2} \mathrm{O}$, and positive end-expiratory pressure at $5 \mathrm{~cm} \mathrm{H}_{2} \mathrm{O}$.

Each set of experiments consisted of a series of trials simulating the three clinical situations with the appropriate $\mathrm{V}_{\mathrm{T}}$ using the different flow rates described above in random order. Each series was performed four times. We made sure that the target $\mathrm{V}_{\mathrm{T}}$ was delivered and increased the pressure limit as needed if necessary. The $\mathrm{ETCO}_{2}$ measurement was stopped when the $\mathrm{ETCO}_{2}$ reading fell below $5 \mathrm{mmHg}$ or when the capnograph stopped displaying values (typically below $6 \mathrm{mmHg}$ ). The elimination time was determined from the digital data exported from the capnograph as the time from onset of ventilation to the point when the $\mathrm{ETCO}_{2}$ value dropped below $8 \mathrm{mmHg}$ for three consecutive breaths. This was an arbitrary cutoff point made necessary by the exponential decline nature of the $\mathrm{CO}_{2}$ elimination curve and the fact that the instrument begins to lose accuracy at very low $\mathrm{CO}_{2}$ levels and stops reporting values below approximately $6 \mathrm{mmHg}$. All measurements were carried out by a single observer (PAK) to eliminate a preventable source of variability.

\section{Statistical analysis}

The digital data were exported from the capnograph software to an Excel spreadsheet, graphed, and visually inspected for consistency and to ensure that there were no evident distortions to the expected exponential decline. The start of 
ventilation and the end point of three consecutive end-tidal values below $8 \mathrm{mmHg}$ were identified. The time difference between the two points was recorded and entered into a spreadsheet for subsequent analysis. Analysis of variance for repeated measures was used to evaluate the effect of different expiratory flows, with $P$ values $<0.05$ considered significant.

\section{Results}

The measurements were highly reproducible and the elimination times were always within $10 \%$ of each other at each setting. There were no significant differences in elimination time even at the lowest setting of $1 \mathrm{~L} / \mathrm{min}$ in each size simulated patient (Table 1). Larger $\mathrm{V}_{\mathrm{T}}$ resulted in a shorter elimination time as would be anticipated, but not to as great an extent as would be predicted from the conventional assumptions about instrumental dead space; doubling of $\mathrm{V}_{\mathrm{T}}$ from $3.5 \mathrm{~mL}$ to $7 \mathrm{~mL}$ reduced the elimination time by a lesser amount than the predicted increase in alveolar ventilation, which is consistent with our previous observations. ${ }^{4}$

\section{Discussion}

To our knowledge, this is the first study to investigate the impact of expiratory flow rate on $\mathrm{CO}_{2}$ elimination in the bench or clinical setting at values relevant to neonatal patients. We found no differences in elimination time between different expiratory flow rates, including the lowest setting of $1 \mathrm{~L} / \mathrm{min}$, indicating that there was no re-breathing even in the extreme situation of the simulated term infant with total MV near $1 \mathrm{~L} / \mathrm{min}$. This finding is consistent with a lack of clinical reports of the adverse effect of VIVE and with a theoretical model prediction. The $1 \mathrm{~L} / \mathrm{min}$ expiratory flow should be just sufficient to provide fresh gas to meet the simulated term infant's needs, as it provides $16.7 \mathrm{~mL}$ of fresh gas/second, slightly exceeding the $16 \mathrm{~mL} \mathrm{~V}_{\mathrm{T}}$ used in this study at a rate of 1 breath/second. We were unable to obtain acceptable recording when we attempted to use $\mathrm{V}_{\mathrm{T}}$ of $18 \mathrm{~mL}$ and $20 \mathrm{~mL}$, with the $\mathrm{ETCO}_{2}$ monitor consistently recording error messages despite careful checking of all connections and repeated re-calibration. This was likely because the $\mathrm{ETCO}_{2}$ monitor algorithm rejected the abnormal $\mathrm{CO}_{2}$ pattern resulting from the effects of the predicted re-breathing of exhaled gas that should occur when the $\mathrm{V}_{\mathrm{T}}$ exceeded available fresh gas supply.

The $\mathrm{V}_{\mathrm{T}}$ we used for the simulated $1.5 \mathrm{~kg}$ and term patients were approximately $4.5 \mathrm{~mL} / \mathrm{kg}$, based on previously published values for $\mathrm{V}_{\mathrm{T}}$ used with volume-targeted ventilation measured at the airway opening, which have been shown to be associated with normocapnia. ${ }^{5-8}$ We used a larger $\mathrm{V}_{\mathrm{T}}$ of $5.8 \mathrm{~mL} / \mathrm{kg}$ for the smallest infant, because, as we previously demonstrated, the tiniest infant requires proportionately larger $\mathrm{V}_{\mathrm{T}}$ to compensate for the fixed instrumental dead space, which becomes proportionately larger in the smallest infant. ${ }^{9}$ The elimination times we found reflected the size of the $\mathrm{V}_{\mathrm{T}}$ in a manner consistent with our previous work in which we demonstrated that effective alveolar ventilation occurs with $\mathrm{V}_{\mathrm{T}}$ at or below the theoretical dead space. ${ }^{4}$ For this study, we reconfigured the setup slightly, which resulted in a slightly smaller instrumental dead space than in our previous study, accounting for the modestly shorter $\mathrm{CO}_{2}$ elimination time recorded in this series of experiments, compared to the original study with $\mathrm{V}_{\mathrm{T}}$ of $3.5 \mathrm{~mL} .{ }^{4}$ For these experiments, we deliberately chose a $\mathrm{V}_{\mathrm{T}}$ that would lead to a relatively long $\mathrm{CO}_{2}$ elimination time, so that we could detect any effect of re-breathing more easily. The remarkable reproducibility of the $\mathrm{CO}_{2}$ elimination times within each series validates the accuracy of this technique in assessing the effective alveolar ventilation.

Our study has some important limitations. We used a simple lung model which is inherently different from a biological lung. The lung model is a passive device, not engaged in $\mathrm{CO}_{2}$ production or gas exchange, or the variable breathing patterns that are seen in preterm infants. Although this may be seen as a limitation, it actually represents an important advantage by eliminating these potential confounders that could obscure the effect of expiratory flow rate on $\mathrm{CO}_{2}$ removal. We were not able to examine the largest possible $\mathrm{V}_{\mathrm{T}}$, which would likely have resulted

Table I $\mathrm{CO}_{2}$ elimination time for the three different "size" patients

\begin{tabular}{|c|c|c|c|c|c|}
\hline & \multicolumn{5}{|c|}{ Expiratory flow rate } \\
\hline & I L/min & $2 \mathrm{~L} / \mathrm{min}$ & $3 \mathrm{~L} / \mathrm{min}$ & $4 \mathrm{~L} / \mathrm{min}$ & $5 \mathrm{~L} / \mathrm{min}$ \\
\hline $\mathrm{V}_{\mathrm{T}}=3.5 \mathrm{~mL}$ & $163.8 \pm 11.3$ & $160.0 \pm 5.0$ & $161.0 \pm 6.3$ & & \\
\hline $\mathrm{V}_{\mathrm{T}}=7.0 \mathrm{~mL}$ & $60.5 \pm 4.2$ & $61.8 \pm 4.8$ & $61.8 \pm 1.5$ & $63.0 \pm 3.2$ & \\
\hline$V_{T}=16 \mathrm{~mL}^{*}$ & $48.5 \pm 5.0$ & $47.5 \pm 3.7$ & $49.3 \pm 3.3$ & $47.5 \pm 3.0$ & $48.3 \pm 3.3$ \\
\hline
\end{tabular}

Notes: Data are presented as mean \pm SD. *Double bellows lung with $90 \mathrm{~mL}$ volume.

Abbreviation: $\mathrm{V}_{\mathrm{T}}$, tidal volume. 
in re-breathing, as the presumed re-breathing rendered the $\mathrm{ETCO}_{2}$ instrument incapable of generating a valid readout based on its signal rejection algorithm. While this conclusion remains speculative, the fact that the failed recordings reproducibly occurred exactly at the point at which re-breathing would be predicted to occur serves as indirect evidence to support the original hypothesis.

\section{Conclusion}

Clinically significant re-breathing will not occur even with expiratory flow rate at the lowest possible setting of $1 \mathrm{~L} / \mathrm{min}$ in all but the largest term infant. VIVE is safe to use even at very low expiratory flows, although its clinical utility has not been established.

\section{Disclosure}

M Keszler has been a consultant to Dräger Medical, the manufacturer of the device used in these studies. He does not have any equity interest in the company and no one related to the company has had any input into the design, execution, or reporting of the study. No financial or equipment support was provided by Dräger Medical for this study.

\section{References}

1. Babylog 8000 Plus Operating Instructions. 3rd ed. Telford, PA: Dräger Medical;2007.

2. Null DM. Dräger Babylog 8000 plus infant care ventilator. In: Donn SM, Sinha SK, editors. Manual of Neonatal Respiratory Care. 2nd ed. Armonk, NY: Mosby Elsevier; 2006:265-268.

3. Kopotic RJ, Mannino FL. Effects of infant ventilator design on spontaneous breathing. J Perinatol. 1987;7(4):298-300.

4. Keszler M, Montaner M, Abubakar K. Effective ventilation at conventional rates with tidal volume below instrumental dead space: a bench study. Arch Dis Child Fetal Neonatal Ed. 2012;97:F188-F192.

5. Dawson C, Davies MW. Volume-targeted ventilation and arterial carbon dioxide in neonates. $J$ Paediatr Child Health. 2005;41(9-10): $518-521$.

6. Herrera CM, Gerhardt T, Claure N, et al. Effects of volume-guaranteed synchronized intermittent mandatory ventilation in preterm infants recovering from respiratory failure. Pediatrics. 2002;110(3):529-533.

7. Lista G, Castoldi F, Fontana P, et al. Lung inflammation in preterm infants with respiratory distress syndrome: effects of ventilation with different tidal volumes. Pediatr Pulmonol. 2006;41(4):357-363.

8. Scopesi F, Calevo MG, Rolfe P, et al. Volume targeted ventilation (volume guarantee) in the weaning phase of premature newborn infants. Pediatr Pulmonol. 2007;42(10):864-870.

9. Nassabeh-Montazami S, Abubakar K, Keszler M. The impact of instrumental dead-space in volumetargeted ventilation of the extremely low birth weight (ELBW) infant. Pediatr Pulmonol. 2009;44(2):128-133.

\section{Publish your work in this journal}

Research and Reports in Neonatology is an international, peer-reviewed, open access journal publishing original research, reports, editorials, reviews and commentaries on neonatal health. The manuscript management system is completely online and includes a very quick and fair peer-review system. Visit http://www.dovepress.com/testimonials.php to read real quotes from published authors. 